\title{
White-Tailed Deer Browsing of Soybeans Significantly Changes Plant Morphology and Reduces Yield, Contributing to Large Financial Losses
}

DANIELLE R. BEGLEY-MILLER, ${ }^{1}$ Department of Ecosystem Science and Management, Pennsylvania State University, University Park, PA, USA; ALAN B. CADY, Department of Biology, Miami University, Oxford, OH, USA

\begin{abstract}
White-tailed deer (Odocoileus virginianus) densities in North America have increased significantly in the last 100 years, contributing to extensive agricultural losses. Smaller farming operations are more likely to be impacted by these losses since they generally are not as financially buffered against poor harvests. This study explores changes in plant growth patterns, percent damage, harvest biomass, and yield of a soybean crop from deer browsing at three exposure levels on a small research farm in southwestern Ohio. Experimental soybean plots protected from deer browsing were placed in $\mathbf{0 . 5}$ hectare fields during the entire 2010 growing season. Similar, but unprotected, control plots were adjacent to these exclosed areas. The exclosure/control areas were assigned a browse exposure level (high, medium, low) based on their proximity to a wooded area. Individually identified plants were sampled by exposure level and treatment (protected vs. unprotected) in July and August measuring height, width, and percent damage. Yield and above-ground biomass were assessed upon harvest in October. Soybean plants protected from deer browsing were 25 percent taller, 87 percent less damaged, yielded 74 percent more seed, and had 47 percent more above-ground biomass than unprotected plants. Browsing exposure level was not significantly different between enclosed and open plots for any plant parameter. Given per-plant yield results and an average planting density, this farm experienced a loss of $\$ 68$ ( \pm $\$ 32)$ per hectare to deer. Overall, that represents a \$405 ( \pm \$214), or 43 percent, financial loss over one growing season.
\end{abstract}

Ohio J Sci 115(2): 56-61

\section{INTRODUCTION}

North American white-tailed deer (Odocoileus virginianus) population sizes have dramatically changed during the last 100 years (Randall and Walters 2011). The species was declining in the early 1900's throughout the United States due to overhunting and habitat loss. In 1970 the Ohio Department of Wildlife estimated there were 17,000 deer in Ohio, but that number soared to 700,000 by 2005 (ODNR Publication 87 2005). Human perceptions of deer impacts to landscapes vary (Lischka et al. 2008), and wildlife managers today are striving to find a balance between maintaining high deer densities for hunters while minimizing this species' impacts on ecosystems and agriculture.

High density deer populations create problems in agricultural areas by consuming food resources outside their traditional forest habitat. The species thrives in exurban areas and, as human occupancy continues to expand, overlap and conflict between humans and deer is expected to increase (Rhoads et al. 2010). Deer often have easy access to crops because they

${ }^{1}$ Address correspondence to Danielle R. Begley-Miller, 435 Forest Resources Building, University Park, PA 16802. E-mail: dfb5098@psu.edu find refuge from hunting by entering residential areas contiguous with agricultural fields (Kays and Tregoning 1995). Restricted hunting seasons and bag limits have exacerbated the effects from lack of natural predators, allowing rapid deer population growth.

Crops are particularly prone to damage where a field edge is exposed to a wooded area, giving easy access for hungry deer (Rieucau et al. 2007). Crops in an Illinois farming region accounted for 84 percent of the surrounding herd's diet in spring months ( 48 percent and 47 percent in summer and fall respectively; Nixon et al. 1991), whereas in Quebec, 12 to 18 percent of crop losses in hay fields were attributed to deer (Richer et al. 2005). Pennsylvania corn crop losses were estimated at approximately 9.9 bushels per hectare based on farmer questionnaires and on-the-ground surveys (Tzilkowski et al. 2002). Furthermore, access to crops increases deer survival rate, placing more foraging stress on surrounding wooded areas during winter months when crops are not available (Stewart et al. 2008). Availability of overwintering food for deer (e.g. food plots, or an edible winter crop) can boost adult female and fawn survival above 80 percent because normal starvation patterns are altered (Smith et al. 2007), intensifying agricultural damage during the next growing season. 
Increasing costs of agricultural production make the economic impact from decreased yield increasingly important, especially for smaller farms not financially buffered against poor harvests. Thus, it is crucial to quantify damage and investigate the timing of deer feeding activity through direct experiments to assess the risk of browsing for smaller farms. Additionally, such data will assist in the development and implementation of deer management strategies aimed at constraining losses at or below an acceptable economic threshold.

Deer damage to crops and the subsequent financial loss is rarely directly quantified, especially in Ohio (Stewart et al. 2007; Vecellio et al. 1994). Most studies of agricultural losses rely on end-of-the-year farmer estimates (Conover 1998; MacGowan et al. 2006) or simulated browsing to quantify deer damage (Garrison and Lewis 1987). Moreover, crop damage is not always consistent throughout the growing season. Putman (1986) found damage from Roe deer foraging on cereal crops was heavier at different times during the growing season, but the overall loss was insignificant because these particular crops are able to recover after heavy browsing in early growth stages.

This study was designed to directly quantify impacts from deer browsing on soybean plant growth and yield on a small farmed research area in southwestern Ohio. There were three main goals: 1) obtain repeated direct measurements of individual plants throughout the growing season to detect changes in growth patterns and browse damage over time, 2) test whether various exposure levels to browsing (based on proximity to a wooded edge) influenced the extent of damage from deer, and 3) assess this farm's financial risk to browsing by comparing yield differences between protected and unprotected plants. These goals address how soybean plants respond to browsing over time, and whether browsing risk should be considered a significant contributor to financial losses.

\section{STUDY AREA}

This study was conducted on 120.5 hectare conservation-tilled fields on the south end of the 69 hectare Miami University Ecology Research Center $\left(39^{\circ} 31^{\prime} 52.8^{\prime \prime} \mathrm{N}, 84^{\circ} 43^{\prime} 22.2^{\prime \prime W}\right)$, located approximately two kilometers northeast of the city of Oxford, Ohio, USA. The climate is temperate and the habitat is classified as deciduous forest, with 930 millimeters of average rainfall and an average temperature of $11^{\circ} \mathrm{C}(\mathrm{NCDC} 2012)$. The fields are 25 meters apart and are arranged in a two-by-six grid on a north-south axis. Five of the fields in the east row have at least one side exposed to a wooded hedgerow 25 meters away, three fields (on the northeast, southeast, and southwest corners) are exposed to woods on two sides, while the other four northernmost fields in the west row have no direct exposure to any wooded areas on any side. Browse exposure classifications of the experimental plots was based on the number of buffered edges between the plot edge and the closest wooded area.

\section{METHODS}

Each of the 120.5 hectare fields was fertilized with 90.6 kilograms of 0-0-60 potash and planted from seed with 2300 Group III Roundup Ready 2 Yield soybeans in May 2010. Fields were then sprayed with Buccaneer glyphosate herbicide (0.38 liters per hectare) to kill weeds, repeating the application in late June ( 0.56 liters per hectare) to kill weeds missed in the first spraying.

A 1.2-by-two meter plot was centered along each of the four edges of each field. The soybeans within these plots were protected from deer browsing following germination by entirely enclosing them in a 2.4 meter tall cage fashioned from 2.5 centimeter mesh galvanized chicken wire. Same-sized control plots containing the control plants were established along each field's edge within two meters of each exclosure and were not caged. These control plants were compared to those in the enclosures. When plants reached 50 centimeters tall, five plants were randomly selected and individually marked in each control and caged plot. These five individuals were sampled in each plot for plant height, width (at widest point), and percent damage [total number of petioles (leaf stems) supporting leaves damaged by deer divided by total number of petioles on the plant] in July and August and then harvested in October.

The impact of deer browsing on soybean yield was determined by hand harvesting and shelling the soybeans from the five focal plants per plot. Yield was recorded as the mean dry biomass (in grams) of seed after drying for two days at $80^{\circ} \mathrm{C}$. To determine aboveground plant biomass, petiole stems were stripped from the main stalks of the same five focal plants and dried for two days at $80^{\circ} \mathrm{C}$. Dried stalks were then weighed 
and their mass recorded. Mean yield and plant biomass from each plot was calculated using the five individual plant measurements.

Mean plant height, width, and percent damage were compared using a three-way ANOVA. Factors were month (two levels: July and August), treatment (two levels: control and caged), and exposure (three levels: high, medium, and low). A two-way ANOVA was used to test for differences in harvest yield and biomass between treatment and exposure levels. All

\section{Table 1}

Means ( $\pm 1 \mathrm{SD}$ ) of soybean plant width $(\mathrm{cm})$ and damage (\%) for July $(n=24)$ and August $(n=24)$ in southwestern Ohio, USA.

Same letters represent no significant differences at the $p$ $<0.05$ level. The $p$ value between groups is listed below the means.

\begin{tabular}{|c|c|c|c|c|}
\hline Month & $\begin{array}{l}\text { Width } \\
\text { (cm) }\end{array}$ & SD & $\begin{array}{c}\text { Damage } \\
(\%)\end{array}$ & SD \\
\hline July & $51^{a}$ & 7 & $3^{a}$ & 4 \\
\hline August & $52^{\mathrm{a}}$ & 7 & $5^{a}$ & 7 \\
\hline$p$ value & 0.51 & NA & 0.06 & NA \\
\hline
\end{tabular}

data were tested to meet parametric assumptions and statistical significance level was set at alpha $\leq 0.05$.

Ultimately, yield losses were converted to monetary values using average planting densities, current soybean price per bushel (\$15 in 2012), and the difference in yield between caged plants and control plants that were exposed to deer browsing. Percent income loss was calculated by extrapolating yield of control and caged plants separately (converted from grams to bushels) at average planting densities across the entire six hectare farm (12 0.5 hectare fields). This approach assumes constant yield across all fields, and calculates farmer income based on those yields. Financial losses were calculated as the difference in income of extrapolated control values minus the difference in extrapolated caged values.

\section{RESULTS}

Plants were 21 percent taller in mid-August $(67 \mathrm{~cm}$ $\pm 12)$ than mid-July $(55 \mathrm{~cm} \pm 8$; Fig. $1 \mathrm{a}$; $p<0.001)$, but there was no detectable difference in plant width or percent damage between months (Table 1).

Protection from browsing resulted in plants that were 25 percent taller (Caged: $68 \mathrm{~cm} \pm 10$; Control: $54 \mathrm{~cm} \pm 9$; Fig. $1 \mathrm{~b} ; p<0.001)$ and 87 percent less damaged (Caged: 1 percent \pm 2 ; Control: 7 percent \pm 6 ; Fig. 1c; $p<0.001)$ than control plants, but there
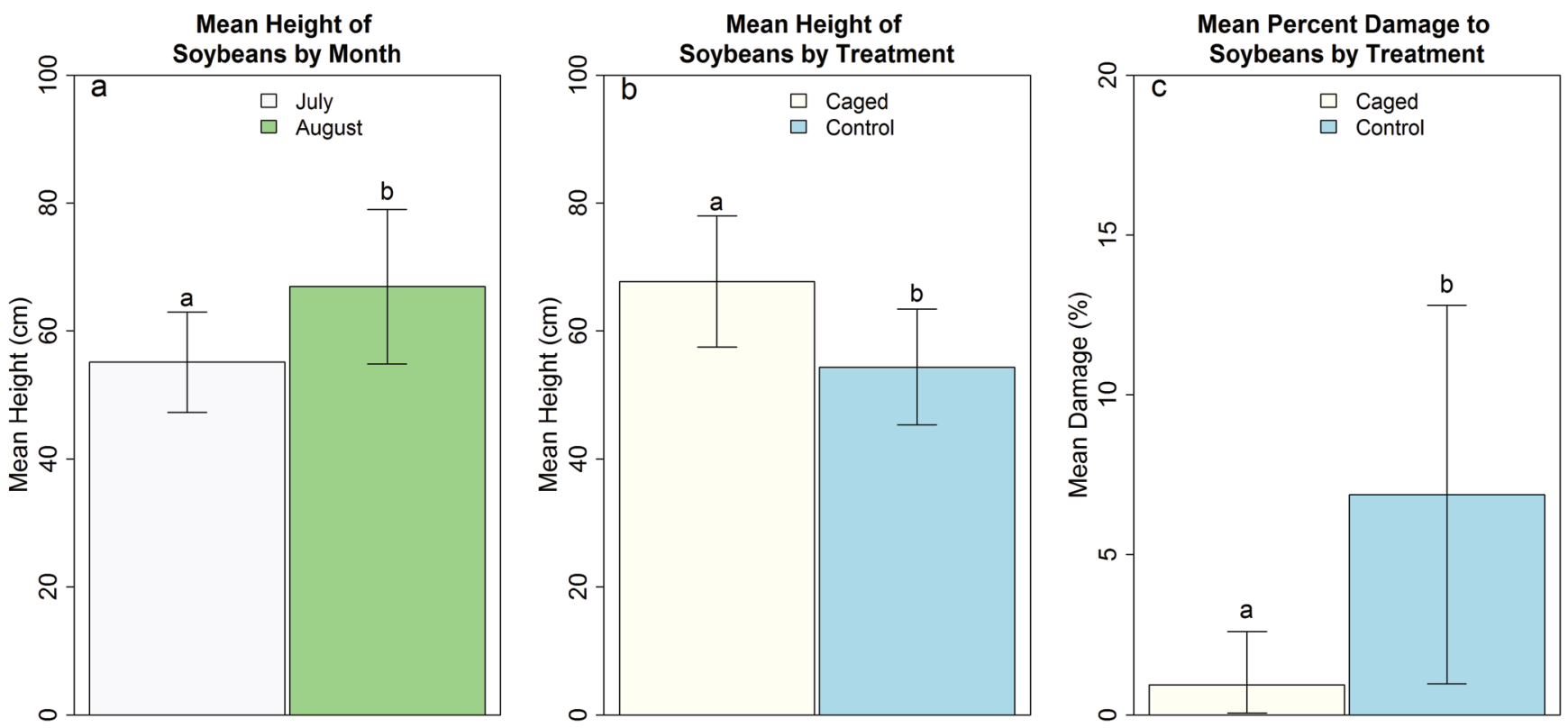

FIGURE 1. Mean ( \pm 1 SD) difference in soybean plant height by month (July and August; $1 \mathrm{a}$ ) and protection from deer-browse (caged and control; 1b). Difference in soybean plant percent damage of deer-browse protected versus unprotected plants (caged versus control; 1c) in southwestern Ohio, USA. Caged plants were protected from deer browsing while control plants were not. Different letters represent statistical significance at the $p<0.05$ level. Letters are not comparable across subfigures. 
were no significant differences in width of protected and unprotected plants (Table 2).

Additionally, caged plants had 74 percent higher yield $(9.20 \mathrm{~g} \pm 3.52)$ versus control plants $(5.28 \mathrm{~g} \pm$ 1.45; Fig. $2 \mathrm{a} ; p=0.002$ ), and had 47 percent more above-ground plant biomass (Caged: $2.68 \mathrm{~g} \pm 0.80$; Control: $1.82 \mathrm{~g} \pm 0.71$; Fig. $2 \mathrm{~b} ; p=0.014)$ than control plants. There were no statistically significant differences in plant height, width, percent damage, yield, or above-ground biomass across the high, medium, and low browse exposure levels (Table 3 ).

Translating yield losses to monetary losses using an average planting density of 40,500 soybean plants

\section{Table 2}

Means ( $\pm 1 \mathrm{SD}$ ) of soybean plant width $(\mathrm{cm})$ and yield $(g)$ for control plants $(n=24)$ and plants protected from deer browsing $(n=24)$ in southwestern Ohio, USA. Same letters represent no significant differences at the $p<0.05$ level. The $p$ value between groups is listed below the means.

\begin{tabular}{ccc}
\hline \hline Treatment & Width (cm) & SD \\
\hline Control & $50^{\mathrm{a}}$ & 8 \\
Caged & $53^{\mathrm{a}}$ & 6 \\
$p$ value & 0.10 & $\mathrm{NA}$ \\
\hline
\end{tabular}

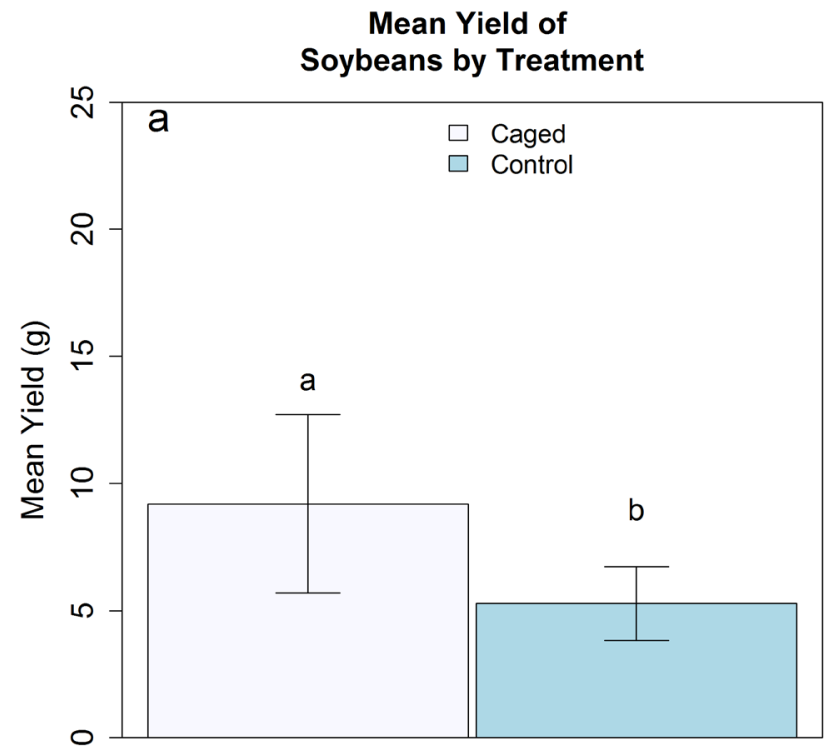

per hectare (Epler and Staggenborg 2008) and an average yield difference of 3.92 grams between control and caged plants (Fig. 2a), produces a 160 kilogram per hectare difference in yield between protected versus unprotected plots. This converts to a loss of approximately $5 \pm 2.4$ bushels per hectare. At $\$ 15$ per bushel (USDA 2012) the total economic loss from deer browsing was approximately $\$ 68 \pm \$ 32$ per hectare.

\section{DISCUSSION}

There was statistically significant lower soybean plant damage (Fig. 1c) and greater plant height, yield, and above-ground biomass (Fig. 1b, Fig. 2a, and Fig. 2b respectively) in areas protected from deer browsing relative to adjacent control plots. Furthermore, while it was confirmed that overall plant height (removing the effect of treatment; Fig. 1a) increased during the growing season, damage and width did not change (Table 1). Comparing plant heights and widths of protected versus unprotected plots provides evidence that deer browsing alters plant growth form. Control plants were significantly shorter than those protected from deer (Fig. 1b), but width did not differ (Table 2). Repeated removal of the apical meristem by deer browsing likely explains this observation. When the meristem is removed, lateral shoots grow more rapidly to re-establish dominance, causing a pruning effect. Over time, plants become bushier and shorter compared to their unbrowsed counterparts.



FIGURE 2. Mean ( \pm 1 SD) difference in soybean plant yield (a) and biomass (b) of plants protected (caged) and unprotected (control) from deer browsing in southwestern Ohio, USA. Different letters represent significant differences at the $p<0.05$ level. Letters are not comparable across subfigures. 
Browsed plants yielded 74 percent less seed and 47 percent less biomass than protected plants (Fig. 2b), suggesting deer browsing directly affects plant production via removal of biomass. These direct losses are statistically significant, but do not consider additional indirect losses to deer via harvest inefficiencies of shorter, bushier plants (Liu 1995). Future studies should consider this effect and work to separate the proportion of direct and indirect losses to deer.

Different browsing exposure levels did not significantly affect plant height, width, percent damage, yield, or biomass (Table 3). This result probably reflects the study design and field configuration. Since experimental fields were discrete, deer had access to all sides of each 0.5 hectare field, exposing more surface area to browsing than would be exposed in a contiguous six hectare field. Redesigning the experiment to collect finer-grained data over shorter time intervals, while focusing on browsing exposure levels, could answer questions about the threshold of browsing tolerated by plants before yield is significantly reduced.

These local data reflect substantial losses of soybean production and subsequent income due to deer browsing. The planted area at this research farm is approximately six hectares divided into 120.5 hectare fields. Given the above analyses, this extrapolates to a loss of $\$ 405( \pm \$ 214)$ per growing season for this farm. If the farm's total income is $\$ 951$ ( $\pm \$ 364$; based on above maximum yield projections), this represents a 43 percent income loss to deer each growing season. These yield losses are probably somewhat higher than would be experienced in traditional contiguous fields since these research fields are divided and deer hunting is prohibited at the station. These analyses do, however, provide an estimate of losses to deer for farming operations less than 12 hectares in size, because they share an increased edge to interior ratio compared to larger farms. Additionally, smaller farms account for approximately 29 percent of all cropland farms in the state of Ohio (USDA Census of Agriculture 2009), meaning such losses have the potential to impact nearly one-third of all farmers in the state.

\section{CONCLUSIONS}

These experimental data clearly demonstrate changes in soybean plant growth morphology resulting from feeding activities by white-tailed deer. These changes lead to primary soybean yield loss and probable secondary costs related to mechanical harvesting, thereby creating substantial economic losses for smaller farming operations. These results clearly demonstrate a need for more effective ways to reduce deer damage in agricultural settings, including, but not limited to, population control and repellent chemicals. Fences, while very effective in preventing deer browsing, are generally not an economically reasonable solution for farmers due to problems with field access and cost (Vercauteren et al. 2006).

Changes in crop management schemes such as trap crops, chemical repellents, or genetically engineering soybean plants to be distasteful could deter deer and decrease losses. Additionally, population control measures via "damage tags" or "nuisance permits" would allow deer herd reduction out of hunting season that is directly proportional to the amount of damage sustained by crops. Issuing such tags and allowing regulated hunting at this research station is recommended at this time to decrease losses to deer. Generally, such policies reduce the feeding pressure

\section{Table 3}

\section{Means ( $\pm 1 \mathrm{SD}$ ) of soybean plant height $(\mathrm{cm})$, width (cm), damage (\%), above-ground biomass ( $\mathrm{g}$ ), and yield ( $\mathrm{g}$ ) for three deer browsing exposure levels (high: $n=25$, medium: $n=11$, and low: $n=12$ ) in southwestern Ohio, USA. Same letters represent no significant differences at the $p<0.05$ level.}

\begin{tabular}{lcccccccccc}
\hline Exposure & Height $(\mathbf{c m})$ & SD & Width $(\mathbf{c m})$ & SD & Damage $(\%)$ & SD & Yield $(\mathbf{g})$ & SD & Biomass $(\mathbf{g})$ & SD \\
\hline High & $65^{\mathrm{a}}$ & 12 & $52^{\mathrm{a}}$ & 5 & $4^{\mathrm{a}}$ & 5 & $6.41^{\mathrm{a}}$ & 1.86 & $2.36^{\mathrm{a}}$ & 0.52 \\
Medium & $60^{\mathrm{a}}$ & 13 & $52^{\mathrm{a}}$ & 10 & $5^{\mathrm{a}}$ & 7 & $6.96^{\mathrm{a}}$ & 2.86 & $2.13^{\mathrm{a}}$ & 0.88 \\
Low & $59^{\mathrm{a}}$ & 10 & $52^{\mathrm{a}}$ & 5 & $3^{\mathrm{a}}$ & 4 & $8.15^{\mathrm{a}}$ & 4.75 & $2.26^{\mathrm{a}}$ & 1.15 \\
\hline
\end{tabular}


on fields but still maintain deer densities at adequate levels for hunting. With increasing costs of farm equipment, fertilizer, and seed, as well as growing demand for crops and increased climate variability, it is crucial to identify and implement ways to control deer browsing in crops.

\section{ACKNOWLEDGMENTS}

Thanks to the Undergraduate Summer Scholars Program at Miami University for funding, the Ecology Research Center at Miami University, R. Kolb for his agricultural expertise and skills, J. Glaccum and J. Whalen for providing their hard work throughout the summer and academic year respectively, and all those who helped with harvesting, including L. Taylor and T. Brown. Thank-you is also extended to T., C., and L. Begley for their help with soybean shelling after harvest, H. Schlotman for her help with statistical analyses in R, and Dr. T. Rooney for his help reviewing earlier drafts. Without the efforts and significant contributions of these people this project would not have been possible.

\section{LITERATURE CITED}

Conover M. 1998. Perceptions of American agricultural producers about wildlife on their farms and ranches. Wildlife Soc B. B26:597-604.

Epler M, Staggenborg S. 2008. Soybean yield and yield component response to plant density in narrow row systems doi:10.1094/ CM-2008-0925-01-RS. Crop Management. Available from: <http://www.plantmanagementnetwork.org/pub/cm/ research/2008/narrow/>. Accessed 17 Aug 2012.

Garrison R, Lewis J. 1987. Effects of Browsing by White-Tailed Deer on Yields of Soybeans. Wildlife Soc B. 15(4): 555-559.

Kays J, Tregoning D. 1995. From Deer Problem to People Solution: A Case Study From Montgomery County, Maryland. Pages 63-76. Proceedings from the Seventh Eastern Wildlife Damage Management Conference. University of Nebraska, Lincoln, NE, USA.

Lischka S, Riley S, Rudolph B. 2008. Effects of Impact Perception on Acceptance Capacity for White-tailed Deer. J Wildlife Manage. 72(2): 502-509.

Liu K. 1995. Soybeans: Chemistry, technology, and utilization, first edition. Aspen: Gaithersburg, MD, USA.

MacGowan B, Humberg L, Beasley J, DeVault T. 2006. Corn and Soybean Crop Depredation by Wildlife. Extension FNR-265-W. Department of Forestry and Natural Resources. Purdue University, IN, USA.

NCDC (National Climatic Data Center), 2012. National Ocean Oceanic and Atmospheric Administration Satellite and Information Service Climate Maps. Available from: <http://hurricane.ncdc.noaa.gov/cgi-bin/climaps/climaps. pl> Accessed 08 Nov 2012.
Nixon C, Hansen, L, Brewer P, Chelsvig J. 1991. Ecology of White-Tailed Deer in an Intensively Farmed Region of Illinois. Wildlife Monogr.118:4-77.

ODNR (Ohio Division of Natural Resources), Division of Wildlife. 2005. Managing Ohio's Deer Herd. Publication \#87. Columbus, OH, USA.

Putman R. 1986. Foraging by Roe Deer in Agricultural Areas and Impact on Arable Crops. J Appl Ecol. 23:91-99.

Randall J, Walters M. 2011. White-tailed deer density effects on vegetation in aspen forest understories over site productivity and stand age gradients. Forest Ecol Manag. 261(3): 408-415.

Rhoads C, Bowman J, Eyler, B. 2010. Home Range and Movement Rates of Female Exurban White-Tailed Deer. J Wildlife Manage. 74:987-994.

Richer M, Onellet J, Lapoin L, Crete M, Huot J. 2005. Impacts of white-tailed deer grazing in hay fields of southern Quebec. Wildlife Soc B. 33:1274-1285.

Rieucau G, Vikery W, Doucet G, Laquerre B. 2007. An innovative use of white-tailed deer (Odocoileus virginianus) foraging behaviour in impact studies. Can J Zoolog. 85:839-846.

Smith J, Sweitzer R, Jensen W. 2007. Diets, Movements, and Consequences of Providing Wildlife Food Plots for WhiteTailed Deer in Central North Dakota. J Wildlife Manage. 71:2719-2726.

Stewart C, McShea W, Piccolo B. 2007. The Impact of WhiteTailed Deer on Agricultural Landscapes in 3 National Historical Parks in Maryland. J Wildlife Manage. 71:15251530 .

Stewart C, Van Deelen T, Dawson J. 2008. Autumn herbivory by white-tailed deer and nutrient loss in planted seedlings Am Midl Nat. 160:342-349.

Tzilkowski W, Brittingham M, Lovallo M. 2002. Wildlife Damage to Corn in Pennsylvania: Farmer and On-the-Ground Estimates. J Wildlife Manage. 66:678-682.

USDA (United States Department of Agriculture). 2012. World Agricultural Supply and Demand Estimates. WASDE - 508 ISSN: 1554-9089. Available from: <http:// www.scribd.com/doc/ 99805876/WASDE-Report-FromUSDA-07-11-2012>. Accessed 17 Aug 2012.

USDA (United States Department of Agriculture). 2009. Census of Agriculture. Ohio. Table 8: Land 2007 and 2002. Available from: <http://www.agcensus.usda.gov/Publications/2007/ Full_Report/Volume_1,_Chapter_1_State_Level/Ohio/ st39_1_008_008.pdf> Accessed 26 Jan 2015

Vecellio R, Yahner G, Storm G. 1994. Crop Damage by Deer at Gettysburg Park. Wildlife Soc B. 22:89-93.

Vercauteren K, Lavelle M, Hygnstrom S. 2006. Fences and DeerDamage Management: A Review of Designs and Efficacy. Wildlife Soc B. 34:191-200. 